\title{
The effect of housing tiestall dairy cows in deep-bedded pens during an 8-week dry period on gait and step activity
}

\author{
E. Shepley* $\odot$ and E. Vasseur $\odot$
}

\section{Graphical Abstract}

\begin{tabular}{|c|c|c|c|}
\hline & Variable & Loose Pen & Tiestall \\
\hline & Gait Attributes & & \\
\hline & Joint Flexion & $-0.43^{a}$ & $+0.23^{b}$ \\
\hline . & Tracking Up & 0.00 & -0.10 \\
\hline Whe & Swinging Out & -0.12 & +0.14 \\
\hline & Asymmetric Step & -0.15 & +0.28 \\
\hline & Reluctance to Bear Weight & +0.15 & +0.28 \\
\hline & Back Arch & -0.02 & 0.00 \\
\hline & Overall Gait & -0.26 & +0.31 \\
\hline
\end{tabular}

a,bSuperscripts denote a significant difference at $P<0.05$.

Green arrows signify gait improvement; red arrows signify worsening gait.

\section{Summary}

Lameness is an issue in the dairy industry that affects both cow welfare and producer profits, especially in stall-based systems. Providing housing that offers good walking conditions for the cow and that increases locomotor activity can benefit joint flexion when walking, reflecting improved joint health. Providing a deepbedded loose-housing option during the dry period is one way for producers to offer the cow an opportunity to improve leg health in preparation for her next lactation with minimal effect on management.

\section{Highlights}

- Housing dry cows in loose pens versus tiestalls did not increase step activity.

- Joint flexion improved for dry cows housed in loose pens and worsened for dry cows housed in tiestalls.

- Cows with higher step activity had better gait regardless of housing system.

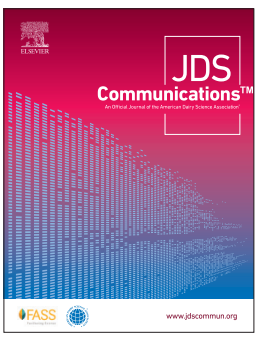

Department of Animal Science, McGill University, Ste-Anne-de-Bellevue, QC H9X 3V9, Canada. *Corresponding author: eshepley1@gmail.com. @ 2021, The Authors. Published by Elsevier Inc. and Fass Inc. on behalf of the American Dairy Science Association ${ }^{\circledast}$. This is an open access article under the CC BY license (http://creativecommons.org/licenses/by/4.0/). Received February 03, 2021. Accepted May 11, 2021. 


\title{
The effect of housing tiestall dairy cows in deep-bedded pens during an 8-week dry period on gait and step activity
}

\author{
E. Shepley* ${ }^{*}$ and E. Vasseur $\odot$
}

\begin{abstract}
Increasing locomotor activity can improve leg health and decrease the prevalence of lameness in dairy cows. The dry period offers an opportunity to provide alternative housing to tiestall (TSL) cows that can increase locomotor activity. The objective was to determine whether housing TSL dairy cows in a deep-bedded loose pen (LP) during the 8-wk dry period affected gait and step activity. Twenty cows, paired by parity and calving date, were assigned at dry-off to a deep-bedded LP or a TSL. Step activity was measured by leg-mounted pedometers. Cows were walked $1 \times /$ wk on a test corridor, and video recordings of gait were taken. Six aspects of gait were scored on a 0-to-5 scale (interval: 0.1 unit): tracking up, joint flexion, back arch, asymmetric step, swing, and reluctance to bear weight. Overall gait was also scored using a 1-to-5 scale (interval: 0.5 unit). Data for gait were analyzed based on the change in gait between dry-off and calving. Daily step data were averaged per week of the dry period. Analyses were performed using a mixed model with treatment, term, and block as fixed effects and cow nested within treatment and block as a random effect for step data. The same model, omitting the fixed effect of week, was used for gait variable analyses. There was no difference in step activity between LP and TSL cows (842.1 \pm 88.86 vs. $799.5 \pm 76.92$ steps/d, LP vs. TSL, respectively). Only joint flexion yielded a treatment difference, with LP cows improving over time and TSL cows worsening $(-0.4 \pm 0.15$ vs. $0.2 \pm 0.15)$. Possibly owing to individual variation in motivation to perform locomotor activity, higher levels of step activity, independent of treatment, tended to be correlated with improvements in swinging out, tracking up, joint flexion, and overall gait score. The increased space allotted to LP cows may have allowed for a larger range of motion for each step, and the denser lying surface may have provided a cushioning effect when transitioning between rising and lying, all of which can improve joint health, reflected in improved joint flexion. Further investigation is warranted into the potential benefits of alternative housing on cow comfort, movement opportunity, and cow condition.
\end{abstract}

$T$ iestall (TSL) housing, common in both the Canadian $(73.8 \%$ of farms; CDIC, 2021) and US (39.3\%; USDA National Animal Health Monitoring System, 2014) dairy industries, is characterized by its restriction of the cow's opportunity to move. In the Canadian industry, TSL housing extends to housing at the time of calving as well; as many as 1 of every 2 cows on TSL farms was reported as calving in a TSL (Vasseur et al., 2010). Housing systems that provide outdoor access are perceived as more welfare friendly by consumers (Cardoso et al., 2016) and are linked to benefits for cow leg health (Regula et al., 2004) and lameness prevalence (Popescu et al., 2013). Transitioning from a TSL system to alternative dairy housing systems cannot be done easily or quickly; however, increasing cow movement opportunity to provide similar benefits may be possible through other housing and management options. For example, providing alternative housing for short durations of time (e.g., 4-wk period at pasture; Hernandez-Mendo et al., 2007) can improve leg health and counter-balance the effects of indoor, stall-based housing systems. Selecting a time in the cow's lactation cycle, such as the dry period, where changes in management and housing are already likely to occur, may likewise be a feasible option for producers while at the same time providing the cow an environment in which she can regain condition before her new lactation.
Our pilot study aimed to determine whether housing TSL dairy cows in deep-bedded loose pens (LP) versus a TSL during an 8 -wk dry period improved aspects of gait and lameness score. We also sought to determine whether LP housing was associated with increases in locomotor activity, measured through average daily number of steps taken by the cow.

This pilot study was part of a larger study evaluating the effect of housing dairy cows in deep-bedded LP in which lying behaviors were the primary study focus (Shepley et al., 2019). The study was conducted at the Macdonald Campus Dairy Unit of McGill University (Sainte-Anne-de-Bellevue, QC, Canada), with ethical animal use approval certified by the Animal Care Committee of McGill University and affiliated hospitals and research institutes (\#20167794). The study met Canadian Council on Animal Care standards.

Twenty TSL-housed Holstein cows were enrolled at dry-off between August 2016 and March 2018. Cows were blocked by parity (mean $\pm \mathrm{SD}=2.1 \pm 1.00$ and $2.6 \pm 1.42$; range $=1-4$ and $1-6$; TSL and LP, respectively) and expected calving date. Cows in each pair were randomly allocated to one of 2 treatment options: LP or TSL. Cows remained in their assigned treatment housing for the duration of an 8-wk dry period (average: 8.3 and $7.5 \mathrm{wk}$ for TSL and LP cows, respectively). Three cows (2 TSL, $1 \mathrm{LP})$ were removed from the study, one due to aborting her calf at the start of the dry period, 
one due to premature dry-off, and a third due to poor temperament that hindered safe handling.

Full details on housing and management practices can be found in Shepley et al. (2019). Briefly, LP treatment housing consisted of individual pens measuring $3.35 \mathrm{~m} \times 4.88 \mathrm{~m}\left(16.35 \mathrm{~m}^{2}\right)$ with a pen base of concrete topped with 1.9-cm-thick rubber mats (Ani-Mats, Ani-Mat Inc.) and bedded with $20 \mathrm{~cm}$ of straw. The TSL treatment housing consisted of stalls measuring $1.41 \mathrm{~m} \times 1.87 \mathrm{~m}$ with a 4.4-cm pasture mat base (longline; Distribution Multi-Mat Inc.) and bedded with $2.0 \mathrm{~cm}$ of wood shavings. Average compressibility, measured via a 10-kg Clegg hammer (Clegg impact soil tester, Lafayette Instrument Co.), of the TSL and LP surfaces was 5.18 Clegg impact value/heavy hammer $(\mathrm{CIV} / \mathrm{H})$ and $4.85 \mathrm{CIV} / \mathrm{H}$, respectively. Lower $\mathrm{CIV} / \mathrm{H}$ denotes higher compressibility. Stall cleaning for TSL housing followed routine management: passing barn staff (average $=15$ passes $/$ d) removed visible contaminants, and fresh wood shavings were added $1 \times / \mathrm{d}$ to maintain $2.0 \mathrm{~cm}$ of bedding. The LP housing was cleaned $1 \times / \mathrm{d}$ in the morning, with fresh bedding added to maintain a $20.0-\mathrm{cm}$ depth, and spot cleaned $1 \times / \mathrm{d}$ in the evening to remove visible manure. All study cows were fed 2 different rations, fed at approximately $0700 \mathrm{~h}$ daily, over the course of the study: a far-off TMR (dry-off until wk 5) and a closeup TMR (wk 6 until calving). Hay was fed ad libitum during the dry period.

Based on the design presented by Franco-Gendron et al. (2016), a test track containing a straight test corridor measuring $1.8 \mathrm{~m}$ wide by $8.1 \mathrm{~m}$ long and covered with rubber mats topped with $1 \mathrm{~cm}$ of wood shavings (Ani-Mats, Ani-Mat Inc.) was created in a designated experimental area. High-speed cameras (120 frames/s, 720p resolution, wide view; GoPro Hero 4, GoPro Inc.) were placed parallel to each side of the test corridor $2.4 \mathrm{~m}$ from the corridor center. Corridors were delineated with high-visibility nylon rope at around $1 \mathrm{~m}$ in height.

A 2-wk period before dry-off and enrollment in the study was used to habituate cows to the experimental area and handling process, in which cows were removed twice per week from their stalls and walked for multiple circuits of the area. Cows displaying poor habituation to the study methodology or confounding health issues were excluded. Upon enrollment, cows were walked in the experimental area once per week following handling protocols detailed in Franco-Gendron et al. (2016), with the exception that cows in the current study were led by halter per farm handling procedure. Cows were walked for a minimum of 5 passages on the test corridor to obtain at least 1 passage in which the cow walked at a consistent pace without stopping. Although not documented, time outside of the treatment housing for both groups generally lasted between 5 and 15 min to obtain a usable passage for gait scoring. High-speed cameras on both sides of the corridor recorded the passages. If needed, grain placed at least $1 \mathrm{~m}$ in front of the cow or an additional handler positioned behind the cow at the point of balance were used to move the cow.

For each cow and week, a gait passage in which the cow was walking at a consistent speed without stopping was selected. Six gait behaviors were scored from video by 2 trained observers: swinging out, back arch, tracking up, joint flexion, asymmetric gait, and reluctance to bear weight (Table 1). Scorers did not know which cows were control and which were treatment. Scores were assigned on a 0 -to-5 scale with 0.1 -unit intervals. An overall gait score was also assigned based on the 1-to-5 numeric rating scale outlined in Flower and Weary (2006), wherein a score of $\geq 3$ was indicative of lameness. Interobserver reliability had a weighted kappa of 0.87 (range: 0.78-0.94), and intraobserver reliability had a weighted kappa of 0.97 (range: 0.90-1.00). Gait was analyzed as the change between the initial and final gait scores for each gait variable.

Step activity was recorded continuously throughout the course of the dry period using a 3-dimensional pedometer (IceTag, IceRobotics) attached on the rear leg of the cow. Pedometer data were retrieved weekly. Data were output in 1-min intervals and presented as the average daily number of steps, based on the summation of

Table 1. Description of visual gait variables and the corresponding endpoints of a visual analog scale (adapted from Flower and Weary, 2006)

\begin{tabular}{|c|c|c|c|}
\hline \multirow[b]{2}{*}{ Gait measure } & \multirow[b]{2}{*}{ Definition } & \multicolumn{2}{|c|}{ Endpoint of visual analog scale ${ }^{1}$} \\
\hline & & 1 & 5 \\
\hline Swinging out & $\begin{array}{l}\text { Degree of side-to-side movement of hind } \\
\text { legs when walking }\end{array}$ & $\begin{array}{l}\text { Hind legs moving in a straight line } \\
\text { during the swing phase }\end{array}$ & $\begin{array}{l}\text { Pronounced, circular motion of the hind } \\
\text { legs during the swing phase }\end{array}$ \\
\hline Back arch & Spine shape when walking & Flat spine & $\begin{array}{l}\text { Convex arch between the withers and } \\
\text { tailbone }\end{array}$ \\
\hline Tracking up & $\begin{array}{l}\text { Gap between footfalls of the front and } \\
\text { rear legs on the same lateral side }\end{array}$ & $\begin{array}{l}\text { Hind hoof falls in the imprint left } \\
\text { by the front hoof }\end{array}$ & $\begin{array}{l}\text { Hind hoof falls short of the front foot } \\
\text { imprint }\end{array}$ \\
\hline Joint flexion & $\begin{array}{l}\text { Degree of extension and flexion of limb } \\
\text { joints when walking }\end{array}$ & All limbs flex and extend easily & $\begin{array}{l}\text { All limbs are stiff and limited in their range } \\
\text { of motion }\end{array}$ \\
\hline Asymmetric step & Evenness of cow's stepping pattern & $\begin{array}{l}\text { Equal steps; footfalls are in an even } \\
\text { "1, } 2,3,4 \text { " rhythm }\end{array}$ & $\begin{array}{l}\text { Not equal; cow places her hooves in an } \\
\text { uneven rhythm }\end{array}$ \\
\hline $\begin{array}{l}\text { Reluctance to bear } \\
\text { weight }\end{array}$ & Amount of weight bearing per leg & Bears weight equally over all legs & $\begin{array}{l}\text { Reluctant to bear equal weight on one or } \\
\text { more limbs }\end{array}$ \\
\hline
\end{tabular}

${ }^{1}$ Where 1 indicates the best possible visual appearance for a gait variable and 5 indicates the worst. 


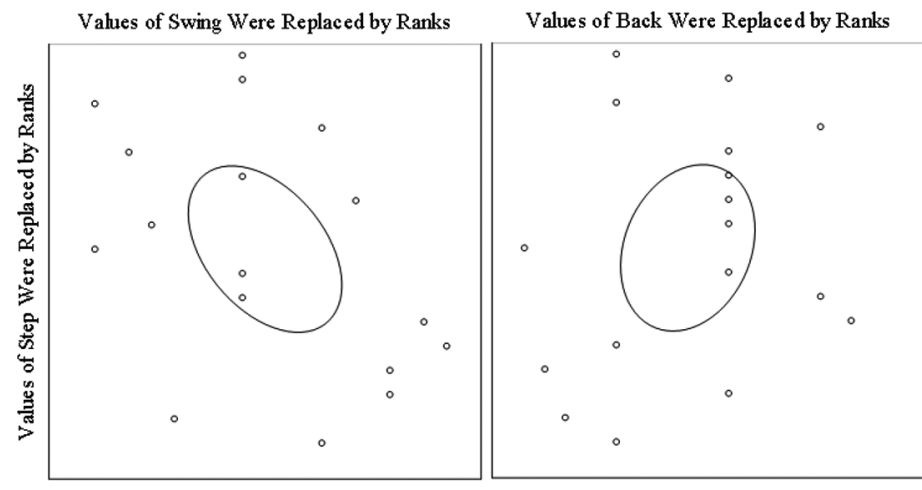

Values of Tracking Were Replace d by Ranks

Values of Flexion Were Replaced by Ranks

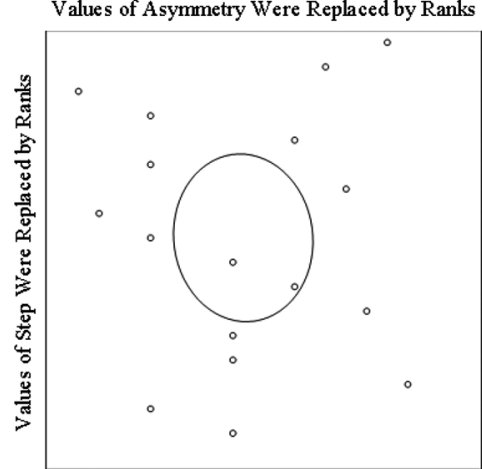

Values of Weight Were Replaced by Ranks

Values of NRS Were Replaced by Ranks
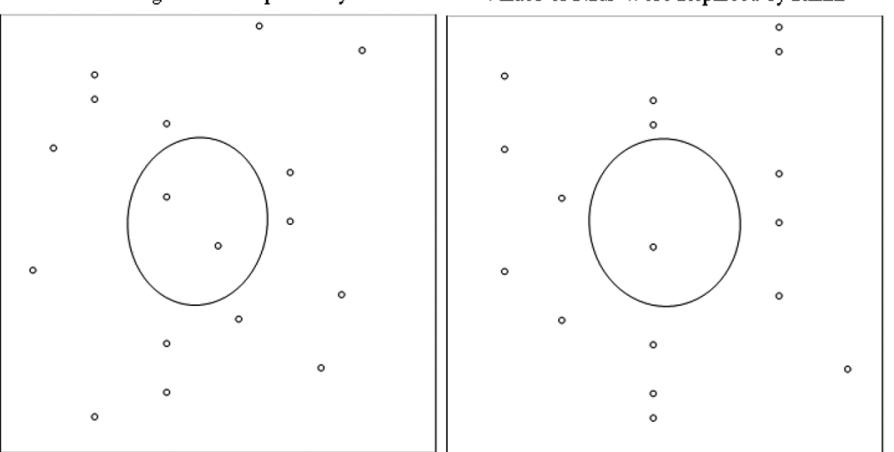

Figure 1. Scatterplot for the Spearman rank correlations between step activity (average no. of steps/d) and variables of gait (swinging out, back arch, tracking up, joint flexion, asymmetric step, and reluctance to bear weight) and overall numeric rating scale (NRS) gait score.

daily activity averaged across each week. Step activity times were analyzed for the early (first week of dry-off), mid (wk 4), and late (last week before calving) terms of the dry period.

All analyses were run in statistical analysis software (SAS 9.4; SAS Institute Inc.) and were conducted at the cow level (n $=8$ for TSL, $\mathrm{n}=9$ for LP) using a mixed model analysis (PROC MIXED and LSMEANS). The analysis of step data included the fixed effects of treatment (TSL, LP), block (1-10), term (early, mid, late), and the interaction between treatment and term. The same model was used for gait, but as we only looked at the change in gait from the beginning to end of the study, the effect of term and its interactions was omitted. The random effect of cow nested within treatment and block was added for the analysis of step activity. Repeated measures for term were analyzed using the best-fit covariance structures (compound symmetry for gait variables and autoregression lag 1 for step activity) and Scheffé's adjustment was used to account for multiple comparisons across terms. A Spearman rank correlation was used to analyze the correlation between step activity and change in gait variable scores. Normality was tested against the residuals for all variables using PROC UNIVARIATE and PROC MIXED. As this study was part of a larger study in which lying behaviors were the primary focus (i.e., Shepley et al., 2019), sample size was selected based on power calculations for lying behaviors. A post hoc power analysis returned 0.87 power for joint flexion $(\alpha=0.05)$ based on the methodology described in Kononoff and Hanford (2006); however, all other variables had a power of $<0.80$.
No difference in step activity was found between LP and TSL treatments ( $818.8 \pm 75.46$ vs. $748.45 \pm 75.59$ steps/d, respectively; denominator degrees of freedom $=6.03, F=0.38, P=0.56)$. In previous studies, increasing the surface area in freestall housing has been found to increase step activity (Telezhenko et al., 2012). The pens in the current study were not designed as exercise areas and, as such, may have lacked the amount of surface area necessary to elicit substantial increases in movement in LP cows compared with other loose-housing systems. However, providing movement opportunity within a housing system does not necessarily provide motivation for the cow to move more (Shepley et al., 2020), and individual cows show considerable differences in their motivation to perform locomotor activity (Alsaaod et al., 2012), which remain consistent across time (Müller and Schrader, 2005). Indeed, independent of treatment, study cows that had higher step activity tended to have greater improvement in the gait variables swinging out $(\mathrm{r}=0.43, P=0.08)$, tracking up $(\mathrm{r}=0.43, P=0.09)$, joint flexion $(\mathrm{r}=0.45, P=0.07)$, and overall gait score $(\mathrm{r}=0.42, P=$ 0.09; Figure 1).

The LP cows showed significant improvement in one attribute of gait (i.e., joint flexion) between the early and late terms of the dry period $(-0.43 \pm 0.147$ vs. $0.23 \pm 0.163$, LP vs. TSL, respectively, $P<0.05$; Table 2$)$. A presumably better step quality (e.g., longer strides, similar number of steps per leg, better surface compressibility) afforded by the LP treatment compared with the more movement-restrictive TSL treatment may have resulted in more joint benefits. For instance, Flower et al. (2007) reported 
Table 2. Mean ( \pm SE) step activity and gait for cows housed in a tiestall (TSL) or loose pen (LP)

\begin{tabular}{|c|c|c|c|c|c|c|}
\hline \multirow[b]{2}{*}{ Variable } & \multicolumn{2}{|c|}{ Treatment } & \multirow{2}{*}{$\begin{array}{l}\text { Difference } \\
\text { of LSM }\end{array}$} & \multirow[b]{2}{*}{$\mathrm{ddf}^{1}$} & \multirow[b]{2}{*}{$F$-value } & \multirow[b]{2}{*}{$P$-value } \\
\hline & LP & TSL & & & & \\
\hline $\begin{array}{l}\text { Step activity }{ }^{2} \text { (no. of steps/d) } \\
\text { Gait }^{3}\end{array}$ & $818.24 \pm 75.461$ & $748.45 \pm 75.589$ & $69.79 \pm 113.320$ & 6.03 & 0.38 & 0.56 \\
\hline Back arch & $-0.02 \pm 0.081$ & $-0.02 \pm 0.090$ & $0.00 \pm 0.123$ & 6 & 0.00 & 1.00 \\
\hline Tracking up & $0.00 \pm 0.122$ & $-0.10 \pm 0.136$ & $0.10 \pm 0.186$ & 6 & 0.29 & 0.61 \\
\hline Joint flexion & $-0.43 \pm 0.147$ & $0.23 \pm 0.163$ & $-0.66 \pm 0.224$ & 6 & 8.65 & 0.03 \\
\hline Overall gait & $-0.26 \pm 0.242$ & $0.31 \pm 0.269$ & $-0.57 \pm 0.369$ & 6 & 2.40 & 0.17 \\
\hline
\end{tabular}

${ }^{1}$ Denominator degrees of freedom.

${ }^{2}$ Presented as the average number of steps/d across the dry period.

${ }^{3}$ Presented as change in gait score between the early (first week of dry-off) and late (last week before calving) terms.

that cows were more confident in their movements, walking with longer strides, and showed improved joint flexion when walking on a more compressible surface like that of the LP treatment. Similarly, more comfortable flooring for standing has been suggested to result in an improvement in overall gait score of more than 1 unit by the end of a 4-wk period on pasture (Hernandez-Mendo et al., 2007). Thus, longer stride lengths that would be more easily achievable in the LP housing, which provides a fuller range of leg movement, may have benefited joint flexion. Moreover, TSL step results may have been overinflated due to the sensitivity of the pedometer to smaller step movements, which may be more likely to occur in TSL compared with LP. Indeed, Shepley et al. (2017) noted that although pedometers were accurately recording steps in TSL compared with visual observations, these steps were defined by smaller leg movements than LP cows would have the ability to exhibit.

Joint flexion may have also been improved in LP cows due to the composition of the deep-bedded straw bases in this housing treatment. Increasing bedding depth has been associated with decreasing lameness prevalence found between deep-bedded straw yards and freestall housing (e.g., 27.1 vs 38.8\%; Barker et al., 2010) as well as improved joint health (Gustafson and LundMagnussen, 1995). In a companion to the current study (Shepley et al., 2019), improvements in the ability to transition between rising and lying as well as the exhibition of a wider variety of lying postures likewise may have been indicative of leg and joint health improvements reported in this study.

The results presented should be interpreted with a degree of caution due to limitations regarding sample size. The sample size for this exploratory study was selected based on required numbers for lying behaviors that were the primary area of interest for this study (i.e., research presented in Shepley et al., 2019), with gait being a secondary area of interest that we wished to explore to generate future hypotheses and research regarding movement opportunity and housing. As we saw numeric improvement in LP cows in other gait attributes, confirmation of the results with a larger sampling of cows may offer further support of the findings.

In conclusion, locomotor activity was not increased by the provision of a deep-bedded LP to TSL-housed dairy cows during the dry period. This level of activity may be affected by external factors, such as the space provided by the housing system in which the cow resides, as well as internal factors, such as the motivation of the individual cow to use the movement opportunity provided. The LP housing resulted in improved joint flexion, which may be attributable to a walking surface more conducive to longer strides, and thus greater joint movement, as well as a lying surface that may be more beneficial for joint health. Releasing TSL-housed cows into a deep-bedded loose-housing system can provide increased comfort and ease of movement to the cow during her dry period as well as an opportunity to regain leg health in preparation for her next lactation.

\section{References}

Alsaaod, M., C. Römer, J. Kleinmanns, K. Hendriksen, S. Rose-Meierhöfer, L. Plümer, and W. Büscher. 2012. Electronic detection of lameness in dairy cows through measuring pedometric activity and lying behavior. Appl. Anim. Behav. Sci. 142:134-141. https://doi.org/10.1016/j.applanim.2012 .10 .001 .

Barker, Z. E., K. A. Leach, H. R. Whay, N. J. Bell, and D. C. Main. 2010. Assessment of lameness prevalence and associated risk factors in dairy herds in England and Wales. J. Dairy Sci. 93:932-941. https://doi.org/10 $.3168 /$ jds.2009-2309.

CDIC (Canadian Dairy Information Centre). 2021. Dairy barn type in Canada. Accessed Jun. 5, 2021. https://agriculture.canada.ca/en/canadas -agriculture-sectors/animal-industry/canadian-dairy-information-centre/ dairy-statistics-and-market-information/farm-statistics/dairy-barns-type.

Cardoso, C. S., M. J. Hötzel, D. M. Weary, J. A. Robbins, and M. A. G. von Keyserlingk. 2016. Imagining the ideal dairy farm. J. Dairy Sci. 99:16631671. https://doi.org/10.3168/jds.2015-9925.

Flower, F. C., A. M. de Passillé, D. M. Weary, D. J. Sanderson, and J. Rushen. 2007. Softer, higher-friction flooring improves gait of cows with and without sole ulcers. J. Dairy Sci. 90:1235-1242. https://doi.org/10.3168/ jds.S0022-0302(07)71612-0.

Flower, F. C., and D. M. Weary. 2006. Effect of hoof pathologies on subjective assessments of dairy cow gait. J. Dairy Sci. 89:139-146. https://doi.org/10 .3168/jds.S0022-0302(06)72077-X.

Franco-Gendron, N., R. Bergeron, W. Curilla, S. Conte, T. DeVries, and E. Vasseur. 2016. Investigation of dairy cattle ease of movement on new methyl methacrylate resin aggregate floorings. J. Dairy Sci. 99:8231-8240. https:/ /doi.org/10.3168/jds.2016-11125.

Gustafson, G. M., and E. Lund-Magnussen. 1995. Effect of daily exercise on the getting up and lying down behaviour of tied dairy cows. Prev. Vet. Med. 25:27-36. https://doi.org/10.1016/0167-5877(95)00496-3.

Hernandez-Mendo, O., M. A. G. von Keyserlingk, D. M. Veira, and D. M. Weary. 2007. Effects of pasture on lameness in dairy cows. J. Dairy Sci. 90:1209-1214. https://doi.org/10.3168/jds.S0022-0302(07)71608-9.

Kononoff, P. J., and K. J. Hanford. 2006. Technical note: Estimating statistical power of mixed models used in dairy nutrition experiments. J. Dairy Sci. 89:3968-3971. https://doi.org/10.3168/jds.S0022-0302(06)72439-0. 
Müller, R., and L. Schrader. 2005. Individual consistency of dairy cow activity in their home pen. J. Dairy Sci. 88:171-175. https://doi.org/10.3168/jds .S0022-0302(05)72675-8.

Popescu, S., C. Borda, E. A. Diugan, M. Spinu, I. S. Groza, and C. D. Sandru. 2013. Dairy cows welfare quality in tie-stall housing system with or without access to exercise. Acta Vet. Scand. 55:43. https://doi.org/10.1186/ 1751-0147-55-43.

Regula, G., J. Danuser, B. Spycher, and B. Wechsler. 2004. Health and welfare of dairy cows in different husbandry systems in Switzerland. Prev. Vet. Med. 66:247-264. https://doi.org/10.1016/j.prevetmed.2004.09.004.

Shepley, E., M. Berthelot, and E. Vasseur. 2017. Validation of the ability of a 3D pedometer to accurately determine the number of steps taken by dairy cows when housed in tie-stalls. Agriculture 7:53-56. https://doi.org/10 3390/agriculture7070053.

Shepley, E., J. Lensink, and E. Vasseur. 2020. A cow in motion: A review of the impact of housing systems on movement opportunity of dairy cows and implications on locomotor activity. Appl. Anim. Behav. Sci. 230: 105026. https://doi.org/10.1016/j.applanim.2020.105026.

Shepley, E., G. Obinu, T. Bruneau, and E. Vasseur. 2019. Housing tiestall dairy cows in deep-bedded pens during an 8-week dry period: Effects on lying time, lying postures, and rising and lying-down behavior. J. Dairy Sci. 102:6508-6517. https://doi.org/10.3168/jds.2018-15859.

Telezhenko, E., M. A. G. von Keyserlingk, A. Talebi, and D. M. Weary. 2012. Effect of pen size, group size, and stocking density on activity in freestallhoused dairy cows. J. Dairy Sci. 95:3064-3069. https://doi.org/10.3168/ jds.2011-4953.

USDA National Animal Health Monitoring System. 2014. NAHMS Dairy 2014: Dairy cattle management practices in the United States. Accessed Aug. 9, 2018. https://www.aphis.usda.gov/animal health/nahms/dairy/.
Vasseur, E., F. Borderas, R. I. Cue, D. Lefebvre, D. Pellerin, J. Rushen, K. M. Wade, and A. M. de Passillé. 2010. A survey of dairy calf management practices in Canada that affect animal welfare. J. Dairy Sci. 93:1307-1315. https://doi.org/10.3168/jds.2009-2429.

\section{Notes}

E. Shepley (D) https://orcid.org/0000-0002-9663-7385

E. Vasseur (1) https://orcid.org/0000-0002-5087-6508

The authors acknowledge the funding support provided by Novalait (Québec, QC, Canada), Dairy Farmers of Canada (Ottawa, ON, Canada), and Valacta (Ste-Anne-de-Bellevue, QC, Canada) as part of the Natural Sciences and Engineering Research Council of Canada (NSERC) Industrial Research Chair in the Sustainable Life of Dairy Cattle. Additional student stipend funding was provided through the Mitacs (Toronto, ON, Canada) Accelerate program.

We extend our gratitude to Roger Cue (McGill University, Ste-Anne-deBellevue, QC, Canada) for his statistical assistance, the staff at the McGill University Macdonald Campus Dairy Unit (Sainte-Anne-de-Bellevue, QC, Canada), and research assistants Tania Wolfe and Athena Zambelis (both of McGill University, Ste-Anne-de-Bellevue, QC, Canada), who assisted in data collection and handling.

The authors have not stated any conflicts of interest. 